\title{
The Efficacy of Brief Intervention Plus Telephone Booster for Alcohol with Depression Out-Patients
}

\author{
Manyardaon J' ${ }^{1}$, Saengcharnchai $\mathrm{P}^{2}$, Leelahanaj $\mathrm{T}^{2 *}$ \\ ${ }^{1}$ ASEAN Institute for Health Development, Mahidol University, Thailand \\ 2 Department of Psychiatry and Neurology, Phramongkutklao hospital, Thailand
}

*Corresponding author: Thawatchai Leelahanaj, MD, M.Sc, Department of

\section{Research Article}

Volume 2 Issue 5

Received Date: October 25, 2017

Published Date: November 08, 2017

Psychiatry and Neurology, Phramongkutklao hospital. Ratchawithi road, Ratchatevee, Bangkok, 10400, Thailand, E-mail: pmkdoc@gmail.com

\section{Abstract}

Objective: Alcohol and comorbid depression commonly occur in patients with alcohol hazardous use. Psychological therapies are required in the treatment and prevention of alcohol abuse. The purpose of this study was to evaluate the effectiveness of Brief intervention plus telephone booster (BI-B) in reducing alcohol consumption and improve outcomes in alcohol with depression.

Method: Participants were recruited using level of alcohol problem and depressive screening test. Alcohol with depression out-patients $(\mathrm{N}=80$ ) were randomly assigned to Treatment as usual (TAU) plus BI-B and only TAU. Data were collected at baseline and 3 months for a pretest-posttest quasi-experimental design. Data were analyzed using descriptive statistics, Chi square and t-test with statistical significant level at 05 .

Results: The results showed that both groups were significant variable between baseline and 3 months follow-up in percentage of heavy drinking days, depressive scores, and level of Gamma-GlutamylTransferase (GGT). In addition, TAU plus BI-B give the better results than only TAU in percentage of heavy drinking days, percentage of abstinence days, depressive scores, and GGT ( $\mathrm{p}<.05)$ at 3 months.

Conclusions: BI-B could be used in the implementation of an optional treatment for patients who need close follow-up.

Keywords: Alcohol with depression; Brief intervention plus telephone booster; Stage of change; Patients; GammaGlutamylTransferase

\section{Introduction}

Alcohol consumption is widely socially gatherings. Alcohol is a psychoactive substance with dependenceproducing properties, which is a significant problem greatly affect social, economic, culture, politic, tourism, medical aspect and national stability. Globally, alcohol consumption results in approximately two billion people.
There is over 76 million people have alcohol use disorders (AUD) [1]. The report of current situation and effect of alcohol consumption in Thailand 2013, conducted by the Center for Alcohol Studies (CAS), has shown that31.5 percent of Thai people aged 15 years and over, or about 17 million drinkers, consume alcohol regularly. Moreover, severe alcohol use was related to depression. The prevalence of AUD and depressive 


\section{Psychology \& Psychological Research International Journal}

illnesses is high in the United States [2]. These disorders worsen depression course, suicide/death risk, social functioning, and health care utilization $[3,4]$. Chronic drinking and depression affect life circumstances (e.g., partner relationship disruptions) [5]. In addition, combining alcohol and antidepressants may also worsen the symptoms of depression [6].

Psychological therapies are required in the treatment and prevention of alcohol abuse. Brief Intervention (BI) has been found to be an effective treatment for reducing the physical and psychiatric illnesses, and social problems. The controlled trials of $\mathrm{BI}$ based on motivational interviewing (MI) can reduce alcohol consumption in psychosis patients and related harm in adults [7-9]. In the efficiency, BI is short duration of treatment for the treatment of individual patients. There are simple steps save cost [10]. BI is more effective than standard care, many studies suggest only BI alone was not sufficient and may dissipate somewhat rapidly over time [11-13]. Therefore, cautious and conservative implementations of BI were importance for motivated to engage in discussions about alcohol use in patients [14]. Booster sessions were recommendation to engage patient either in person or via phone [15]. Which BI plus a telephone booster with personalized feedback led to longterm reductions in alcohol intake among heavy drinkers admitted to the hospital for treatment of an injury [16].

The objective of this study was to evaluate the effectiveness of Brief intervention plus telephone booster (BI-B) in reducing alcohol consumption and improve outcomes in alcohol with depression at Psychiatry-OPD.

\section{Method}

\section{Participants}

Eligible patients were: adult (18 years or older), male, score on the Alcohol Use Disorder Identification Test (AUDIT)more than 7 and confirmed diagnosed with Alcohol use disorder (AUD) following DSM-V by Psychiatrist, the researcher able to contact them, ability to provide informed consent, registration as patient in the Psychiatry-OPD during study screening hours. Other exclusion criteria were significant impairment of cognition or judgment rendering the person in capable of informed consent. (e.g. traumatic brain injury, delirium, intoxication), and current engagement in alcohol inpatient treatment.

The study was verified from Mahidol University Social Sciences and Humanities Institutional Review Board MU-
SSIRB (2015/337) and Institute Review Board Royal Thai Army Medical Department (Q030q/58). All enrolled participants gave their written informed consent.

\section{Study Design}

This study is a pretest-posttest Quasi-experimental design and comparing the effectiveness of TAU plus BI-B and only TAU for reduce alcohol consumption and improve outcomes in alcohol with depression outpatients. Forty patients were selected for each TAU plus BI-B and only TAU. Patients with odd numbers were assigned in TAU plus BI-B while even number samples in only TAU.

\section{Intervention}

Brief intervention plus telephone booster (BI-B): The patients were received a 15-30 minutes counseling sessions with a nurse giving personalized feedback from AUDIT score and motivating change using Motivational Interviewing techniques for BI [17]. Then the patients received BI was provided telephone boosters 2 sessions, each session approximately 15 minutes long, telephone boosters 2 sessions comprise:

- Session 1 (Day7 after receive BI): The goal of the first booster call is to re-engage the patient, reinforce the change plan originated in Psychiatry-OPD, explore potential barriers to change and support continuing efforts at change and seek a commitment from them.

- Session 2 (Day28 after receive BI): The goal of the second booster call is to check-in and address barriers to treatment engagement, ask about process to deal with problem drinker, review change plans, reinforce motivation.

Treatment as usual (TAU): The study is being conducted at Psychiatry-OPD Phramongkutklao hospital that regularly assists patient with alcohol. They already have an established protocol for treating alcohol. This could include patient-centered therapy, medications and Psycho-education. The participants were received brief advice and health education which took approximately 510 minutes.

\section{Baseline and 3 Months Follow-Up Measures}

Timeline follow-back (TLFB): The Alcohol TLFB was developed by Sobell and Sobell (2013) and has been translated into Thai languages by Soontaree Srikosai (2014) [18]. The TLFB is a calendar of 1 month that provides visual cues to aid patients in retrospective recall of behavior. Researcher asks them to estimate their daily alcohol consumption over a designated time interval. In 


\section{Psychology \& Psychological Research International Journal}

our study, we were assessing the percentage of heavy drinking day, percentage of abstinence day in previous 4 weeks. Clinically, the TLFB can be used to provide feedback about one's drinking in an effort to increase a client's motivation to change [19].

The Stage of change (Readiness Ruler): The simplest ways to assess a patient's readiness to change their drinking is to use the Readiness Ruler recommended by [20]. The patients who score in the lower end of the scale are pre-contemplation. Those who score in the middle range 4-6 are contemplations, and those scoring in the higher range should be considered ready to take action). It is helpful to begin counseling in a way that meets the patient's current motivation level [21].

Depressive screening test: Depressive screening test developed by Department of Mental health (2014). The item screens patients for depression in previous 2 weeks. This well validated measure reliability detects depression in adults at cut-off of $\geq 6$ [22].

Gamma-GlutamylTransferase (GGT): GGT has been widely used as a marker for alcohol use in epidemiologic studies (Whitfield, 2001). We collected data from routine clinical care at Psychiatry-OPD. The normal range of GGT is 0-50 U/L [23].

\section{Statistical Analyses}

Descriptive Statistics (frequency, percentage, mean and standard deviation) and the Chi-square were used to determine any within and between group differences depending on the categorical and/or continuous nature of the variables of interest. The comparability in pre-post intervention within group was used pair t-test and in post intervention between groups was used independent ttests. Statistical significance was set at p-value $=.05$.

\section{Results}

\section{Characteristic of Patients}

of the 80 patients were eligible and completed the screening questionnaire, 5 patients were lost between intervention and follow-up. Each reason was classified as not able to contact them when 3 months follow-up (2 patients) and current engagement in alcohol in-patient treatment (3 patients).

Table 1 shows the characteristics of the patients. All of patients were male (100\%), with means age of $44.05 \pm$ $10.665(27-69)$ years and 46.18 \pm 11.054 (21-77) years in the TAU and TAU plus BI-B group, respectively. The patients in TAU were single $47.5 \%$ while the patients in TAU plus BI-B group were married 62.5\%.In part of educational, most of patients in TAU finished senior high school or vocational certificate $45 \%$ and in TAU plus BI-B group finished high vocational certificate $25 \%$. The majority of their occupation is government officer $(52.5 \%$ TAU, 50\% TAU plus BI-B group). However, there was no statistically significant difference in this parameter.

\begin{tabular}{|c|c|c|c|}
\hline \multirow[b]{2}{*}{ Characteristic } & \multicolumn{3}{|c|}{ Study condition } \\
\hline & $\begin{array}{c}\text { TAU } \\
\text { N (\%) }\end{array}$ & $\begin{array}{c}\text { TAU plus BI-B } \\
\text { N (\%) }\end{array}$ & p-value \\
\hline $\begin{array}{l}\text { Age }(\text { mean } \pm \text { SD }) \\
\text { Min } \\
\text { Max }\end{array}$ & $\begin{array}{c}44.05 \pm 10.665 \\
27 \\
69\end{array}$ & $\begin{array}{c}46.18 \pm 11.054 \\
21 \\
77\end{array}$ & .384 \\
\hline $\begin{array}{c}\text { Marital status } \\
\text { Single } \\
\text { Married } \\
\text { Divorced } \\
\end{array}$ & $\begin{array}{c}19(47.5) \\
15(37.5) \\
6(15) \\
\end{array}$ & $\begin{array}{c}10(25) \\
25(62.5) \\
5(12.5) \\
\end{array}$ & .068 \\
\hline $\begin{array}{c}\text { Educational level } \\
\text { Primary school } \\
\text { Secondary school } \\
\text { Senior high school or Vocational- Certificate } \\
\text { High Vocational Certificate } \\
\text { Bachelor's Degree } \\
\geq \text { Bachelor's Degree }\end{array}$ & $\begin{array}{l}9(22.5) \\
4(10.0) \\
18(45) \\
7(17.5) \\
2(5.0) \\
0(0)\end{array}$ & $\begin{array}{l}3(7.5) \\
8(20.0) \\
9(22.5) \\
10(25) \\
8(20.0) \\
2(5.0)\end{array}$ & $.019 *$ \\
\hline $\begin{array}{c}\text { Baseline data about alcohol } \\
\text { Family history of alcohol use } \\
\text { Yes }\end{array}$ & $20(50)$ & $24(60)$ & .369 \\
\hline
\end{tabular}

Leelahanaj T, et al. The Efficacy of Brief Intervention Plus Telephone Booster for Alcohol with Depression Out-Patients. Psychol Psycholgy Res Int J 2017, Copyright $@$ Leelahanaj T, et al. 2(5): 000136 


\section{Psychology \& Psychological Research International Journal}

\begin{tabular}{|c|c|c|c|}
\hline No & $20(50)$ & $16(40)$ & \\
\hline Age onset (mean \pm SD) & $19.08 \pm 5.151$ & $18.53 \pm 4.685$ & \multirow{3}{*}{.619} \\
\hline Min & 13 & 12 & \\
\hline Max & 37 & 40 & \\
\hline Lifetime of drinking (mean \pm SD) & $25.23 \pm 10.391$ & $27.65 \pm 9.431$ & \multirow{3}{*}{.278} \\
\hline Min & 3 & 8 & \\
\hline Max & 49 & 41 & \\
\hline Type of alcohol intake & & & \multirow{7}{*}{.751} \\
\hline Whisky (35\% vol.) & $13(32.5)$ & $17(42.5)$ & \\
\hline Rice whisky 40\% & $10(25.0)$ & $6(15.0)$ & \\
\hline Beer5\%; Singha, Heinegen, Leo & $12(30.0)$ & $10(25.0)$ & \\
\hline Beer6.4\% ;Chang & $4(10.0)$ & $4(10.0)$ & \\
\hline Wine $12 \%$ & $0(0)$ & $1(2.5)$ & \\
\hline Native liquors,Ya Dong liquor 6\% & $1(2.5)$ & $2(5.0)$ & \\
\hline Frequencies : Every day & $18(45)$ & $21(52.5)$ & \multirow{6}{*}{.116} \\
\hline 3-4 days per week & $2(5.0)$ & $6(15)$ & \\
\hline 2-3 days per month & $8(20)$ & $1(2.5)$ & \\
\hline Almost everyday & $5(12.5)$ & $5(12.5)$ & \\
\hline 1-2 days per week & $3(7.5)$ & $5(12.5)$ & \\
\hline 1day per month & $4(10)$ & $2(5.0)$ & \\
\hline $\begin{array}{c}\text { Alcohol use per day: } \\
\text { Standard drinks (mean } \pm \text { SD) }\end{array}$ & $9.90 \pm 6.062$ & $10.74 \pm 5.928$ & \multirow{3}{*}{.534} \\
\hline Min & 1 & 2 & \\
\hline Max & 26 & 26 & \\
\hline AUDIT score $($ mean \pm SD) & $23.10 \pm 8.69$ & $24.58 \pm 7.56$ & \multirow{4}{*}{.101} \\
\hline Hazardous drinker (score 8-15) & $13(32.5)$ & $6(15)$ & \\
\hline Harmful drinker (score 16-19) & $4(10)$ & $9(22.5)$ & \\
\hline Suspected of possible alcohol dependence (score 20-40 & $23(57.5)$ & $25(62.5)$ & \\
\hline
\end{tabular}

Note. ${ }^{*}$ p $<.05$

Table 1: Baseline characteristics of the patients $(\mathrm{N}=80)$

Majority of patients had family history of alcohol use $50 \%$ in TAU and $60 \%$ in TAU plus BI-B. The mean of age onset were 19.08 5.151 (13-37) years in TAU and 18.53 \pm 4.685(12-40) years in TAU plus BI-B. Lifetime of drinking was $25.23 \pm 10.391$ (3-49) years in TAU and 27.65 \pm 9.431(8-41) years in TAU plus BI-B. The type of alcohol intake was whisky ( $35 \%$ vol.) ( $32.5 \%$ in TAU, $42.5 \%$ in BIB).Alcohol consumption, in TAU consumed 9.90 $\pm 6.062(1-$ 26) standard drinks per day on average and in TAU plus BI-B average 10.74 \pm 5.928(2-26)standard drinks consumed per day on average, and most of patients in both groups were drinking frequently every day $(45 \%$ TAU, 52.5\% TAU plus BI-B). There were no statistically significant differences for baseline data about alcohol of the patients between groups ( $p>.05)$.

The mean AUDIT score of patients were 23.10 (S.D. = 8.69) in TAU and 24.58 (S.D. = 7.56) in TAU plus BI-B. Most patients in TAU were suspected of possible alcohol dependence $57.5 \%$ and $62.5 \%$ in TAU plus BI-B. The hazardous drinkers were $32.5 \%$ in TAU and $15 \%$ in TAU plus $\mathrm{BI}-\mathrm{B}$, in parts of harmful drinker were $10 \%$ in TAU and $22.5 \%$ in TAU plus BI-B. However, statistic significant different in this parameter was not evident ( $p>.05)$.

\section{Effectiveness of the intervention on clinical outcome of the patients}

The table 2 shows the results at baseline and 3 months follow-up. Regardless of intervention, there were significant variable between baseline and 3 months follow up within TAU plus BI-B. Percentage of heavy drinking days, depressive scores, and level of GGT were decreased and percentage of abstinence days was increased $(\mathrm{p}<$ $.001)$. Readiness ruler was improved $(\mathrm{p}<.05)$. While within TAU, a significant variables between baseline and 3 months follow up are as follows: percentage of heavy drinking days were decreased $(\mathrm{p}<.05)$, depressive scores and level of GGT were decreased were decreased $(\mathrm{p}<$ $.001)$. 


\section{Psychology \& Psychological Research International Journal}

\begin{tabular}{|c|c|c|c|c|c|c|}
\hline \multirow{2}{*}{ Measure } & \multicolumn{3}{|c|}{$\begin{array}{c}\text { TAU } \\
\text { (mean } \pm S D)\end{array}$} & \multicolumn{3}{|c|}{$\begin{array}{l}\text { TAU plus BI-B } \\
\text { (mean } \pm \text { SD) }\end{array}$} \\
\hline & Baseline & $\begin{array}{l}3 \text { months follow- } \\
\text { up }\end{array}$ & p-value & Baseline & $\begin{array}{c}\text { months follow } \\
\text { up }\end{array}$ & p-value \\
\hline $\begin{array}{c}\text { Percentage of heavy drinking } \\
\text { days }\end{array}$ & $\begin{array}{c}59.77 \\
\pm 40.83\end{array}$ & $40.50 \pm 36.53$ & $.015^{*}$ & $\begin{array}{c}70.17 \\
\pm 31.20\end{array}$ & $10.75 \pm 15.31$ & $.000^{* *}$ \\
\hline $\begin{array}{c}\text { Percentage of abstinence } \\
\text { days }\end{array}$ & $\begin{array}{c}38.98 \\
\pm 39.78\end{array}$ & $\begin{array}{r}52.08 \\
\pm 37.67\end{array}$ & .080 & $\begin{array}{r}27.28 \\
\pm 32.14\end{array}$ & $79.58 \pm 30.22$ & $.000^{* *}$ \\
\hline Depressive scores & $\begin{array}{c}9.83 \\
\pm 3.11\end{array}$ & $\begin{array}{c}7.20 \\
\pm 3.52 \\
\end{array}$ & $.000^{*}$ & $\begin{array}{c}8.80 \\
\pm 3.12 \\
\end{array}$ & $\begin{array}{c}4.55 \\
\pm 3.49\end{array}$ & $.000^{*}$ \\
\hline Readiness ruler & $\begin{array}{c}7.10 \\
\pm 2.67\end{array}$ & $\begin{array}{l}7.40 \\
\pm 2.15\end{array}$ & .533 & $\begin{array}{c}6.68 \\
\pm 2.90\end{array}$ & $\begin{array}{c}7.90 \\
\pm 2.12\end{array}$ & $.035^{*}$ \\
\hline $\begin{array}{c}\text { Stage of change } \\
\text { Pre-contemplation (\%) } \\
\text { Contemplation (\%) } \\
\text { Determination (\%) }\end{array}$ & $\begin{array}{c}5(12.5) \\
10(25) \\
25(62.5)\end{array}$ & $\begin{array}{c}1(2.5) \\
15(37.5) \\
24(60)\end{array}$ & & $\begin{array}{c}7(17.5) \\
11(27.5) \\
22(55)\end{array}$ & $\begin{array}{c}1(2.5) \\
10(25) \\
29(72.5)\end{array}$ & \\
\hline GGT & $\begin{array}{c}271.80 \\
\pm 255.09\end{array}$ & $\begin{array}{c}182.45 \\
\pm 194.59\end{array}$ & $.002^{*}$ & $\begin{array}{c}250.33 \\
\pm 238.72\end{array}$ & $\begin{array}{c}108.85 \\
\pm 112.85\end{array}$ & $.000^{*}$ \\
\hline
\end{tabular}

Note. ${ }^{*} \mathrm{p}<.05,{ }^{* *} \mathrm{p}<.001$

Table 2: Outcomes measures at baseline and 3 months follow-up

The comparable between groups at 3 months follow-up as can be seen in the table 3. TAU plus BI-B showed significantly percentage of heavy drinking days and depressive scores were decreased $(\mathrm{p}<.001)$, percentage of abstinence days were increased $(\mathrm{p}<.001)$, and level of GGT were decreased $(\mathrm{p}<.05)$ more than the TAU. While, there were no statistically significant differences for readiness ruler between two groups $(\mathrm{p}=.298)$.

\begin{tabular}{|c|c|c|c|}
\hline \multirow{2}{*}{ Measure } & \multicolumn{3}{|c|}{ Difference between groups at 3 months follow-up } \\
(mean \pm SD)
\end{tabular}

Note. ${ }^{*} \mathrm{p}<.05,{ }^{* *} \mathrm{p}<.001$

Table 3: Difference between groups regarding outcomes measures at 3 months follow-up

At 3 month follow-up, 75 (93.75\%) cases completed the intervention (TAU group 36 patients and TAU plus BIB group 39 patients).Reasons were classified as not able to contact them when 3 months follow-up (2 patients) and current admit in alcohol in-patient treatment (3 patients). At 6 month, $63(78.75 \%)$ cases could contact (29 patients in TAU group and 34 patients in TAU plus BI$\mathrm{B}$ group).The abstinence rate was showed in figure 1 . The results showed decrease abstinence rates in both groups. For the TAU group, the abstinence rates were decreased from $45 \%$ at 3 months to $35 \%$ at 6 months. Similarly, in the TAU plus BI-B group were decreased from $70 \%$ at 3 months to $55 \%$ at 6 months.

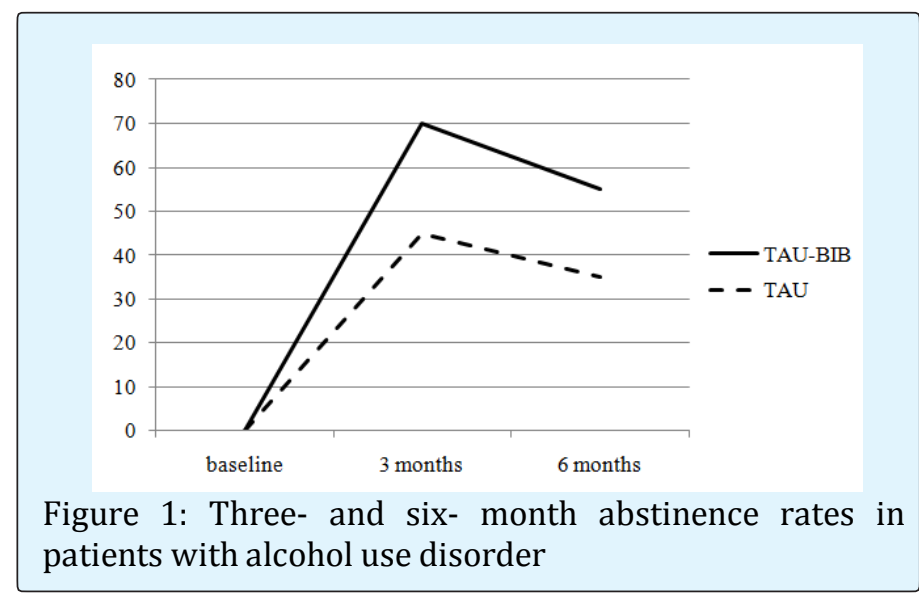




\section{Psychology \& Psychological Research International Journal}

\section{Discussion}

TAU plus BI-B were more effective at achieving reduce alcohol consumption and improve outcomes (stage of change, decreased level of GGT and decreased depressive score) than TAU at 3 months follow up. The effective in TAU plus BI-B was supported by Longabaugh, et al. (2001) showed that the patients receiving BI-B, reduced alcohol-related negative consequences and alcoholrelated injuries more than standard care group [24]. Milner, et al. (2010) reported that the BI is effective in reduced alcohol consumption in-patients who screen positive for at-risk drinking in the psychiatric emergency setting. Previous research from Freyer-Adam, et al. (2008) reported that the efficacy of a brief alcohol intervention on in-patients had positive effects on readiness to change drinking and readiness to seek formal help for alcohol problems. This study choose BI plus telephone boosters because telephone booster sessions after BI can remind patient of the intervention and telephone booster sessions can cost savings to the hospital. Although, the abstinence rates in TAU plus BI-B group were decreased more than TAU group at 6-month follow-up but the patients in TAU plus BI-B group could contacted more than TAU group [25]. However, the abstinence rate was decreased in both groups but the contact patients in TAU plus BI-B more than TAU. The possible reason may explain from patient-researcher relationship. Norcross and Wampold (2011) described in Evidence based therapy relationships research conclusions and clinical practices about practice recommendations, practitioners are encouraged to routinely monitor patient's responses to the therapy relationship and ongoing treatment which increased opportunities to reestablish collaboration, improve the relationship, modify technical strategies, and avoid premature termination [26].

Interestingly, the stage of change in the TAU plus BI-B from baseline to 3 month follow-up was increased $16.8 \%$ in determination stage. Our data was supported by Connors et al (2001) described BI base on MI prevent the backward move from determination stage to contemplation stage that might be a factor that induces relapse. Moreover, the increased or maintains individuals' readiness to change was important premise for behavior change $[27,28]$.

Besides this study reported that TAU plus BI-B reduced alcohol consumption, found that the statistically significant improvement seen in the domain of clinical outcome (the level of GGT was decreased significant at a level of $\mathrm{p}<.01$ both in TAU and TAU plus BI-B at 3-month follow-up). From the studies of Mundle et al (1999) Helander and Tabak off (1997) found that the laboratory marker for alcohol consumption (e.g. CDT, GGT and mean corpuscular volume (MCV)), the level of GGT was the most sensitive marker for alcoholism $[29,30]$.

The results in this study found that depressive scores were decreased in both groups. The possible reason might be because extraneous variable such as the medication which the patients received. Almost patients in both groups were received the same with medication such as vitamin supplement (vitamin B complex or vitamin B 1-612), folic acid, antidepressant (sertraline, fluoxetine, trazodone) and benzodiazepines (diazepam, lorazepam, and clonazepam). This was limitation in this study.

From this finding, TAU plus BI-B could be used to implement as an optional treatment for patients who need close follow-up. These treatments are more likely to be useful for patients in contemplation stage. The duration time is use for 30 minutes of BI at PsychiatryOPD and 15 minutes of each of telephone booster. In the future, the professionals can employ the technique to assist the alcohol with depression patient for reducing alcohol consumption and improving outcomes.

In conclusion, TAU plus BI-B is effectiveness in reduced alcohol consumption and improved out comes in alcohol with depression. The further study could be study in the relationship patient-therapist for support to the intervention.

\section{Acknowledgement}

This work was supported by Center for Alcohol Studies N0.59-A2-0002.The authors would like to especially thank Dr. Doungjai Buntup and Dr. Prapapun Chucharoen for their support, guidance, and unrelenting support throughout this process. Thanks to Department of Psychiatry and Neurology, Phramongkutklao hospital for their assistance with this project.

\section{References}

1. World Health Organization (2004).Global status report on alcohol 2004. World Health Organization, Geneva, Switzerland.

2. Center for Behavioral Health Statistics and Quality (2011) Results from the 2010 National Survey on Drug Use and Health: Summary of national findings (HHS Publication No. SMA 11-4658, NSDUH Series H- 


\section{Psychology \& Psychological Research International Journal}

41). Rockville, MD: Substance Abuse and Mental Health Services Administration.

3. DeVido JJ, Weiss RD (2012) Treatment of the depressed alcoholic patient. Current psychiatry reports 14(6): 610-618.

4. Grant BF, Stinson FS, Dawson DA, Chou SP, Dufour MC, et al. (2004) Prevalence and co-occurrence of substance use disorders and independent mood and anxiety disorders: results from the National Epidemiologic Survey on Alcohol and Related Conditions. Arch Gen Psychiatry 61(8): 807-816.

5. Sullivan LE, Fiellin DA, O'Connor PG (2005) The prevalence and impact of alcohol problems in major depression: a systematic review. American medical journal 118(4): 330-341.

6. Nierenberg C (2013) Holiday Drinking: How 8 Common Medications Interact with Alcohol.

7. Milner KK, Barry KL, Blow FC, Welsh D (2010) Brief interventions for patients presenting to the Psychiatric Emergency Service (PES) with major mental illnesses and at-risk drinking. Community mental health journal 46(2): 149-155.

8. McQueen J, Allan L, Mains D (2006) Brief Motivational Counseling for Alcohol Abusers admitted to Medical Wards. British Journal of Occupational Therapy 69(7): 327-333.

9. Hettema J, Steele J, Miller WR (2005) Motivational interviewing. Annu Rev Clin Psychol 1: 91-111.

10. Osilla KC, Cruz E dela, Miles JNV, Zellmer S, Watkins K, et al. (2010) Exploring Productivity Outcomes from a Brief Intervention for At-Risk Drinking in an Employee Assistance Program. Addictive Behaviors 35(3): 194-200.

11. McCambridge J, Strang J (2004) The efficacy of singlesession motivational interviewing in reducing drug consumption and perceptions of drug-related risk and harm among young people: results from a multisite cluster randomized trial. Addiction 99(1): 39-52.

12. Williams S, Brown A, Patton R, Crawford MJ, Touquet $\mathrm{R}$ (2005) The half-life of the 'teachable moment' for alcohol misusing patients in the emergency department. Drug Alcohol Depend 77(2): 205-208.

13. Tantirangsee N, Assanangkornchai S, Marsden J (2015) Effects of a brief intervention for substance use on tobacco smoking and family relationship functioning in schizophrenia and related psychoses: a randomised controlled trial. Journal of substance abuse treatment 51: 30-37.

14. Nilsen P, Baird J, Mello MJ, Nirenberg T, Woolard R, et al. (2008) A systematic review of emergency care brief alcohol interventions for injury patients. Journal of substance abuse treatment 35(2): 184-201.

15. Edwards JR, Lambert LS (2007) Methods for integrating moderation and mediation: A general analytical framework using moderated path analysis. Psychol Methods 12: 1-22.

16. Field C, Walters S, Marti CN, Jun J, Foreman M, et al. (2014) A multisite randomized controlled trial of brief intervention to reduce drinking in the trauma care setting: how brief is brief? Annals of surgery 259(5): 873-880.

17. Babor TF, Higgins-Biddle JC (2001) Brief Intervention for Hazardous and Harmful Drinking: A Manual for use in Primary Care. World Health Organization, Document No. WHO/MSD/MSB/01.6b. Pp: 53.

18. Soontaree Srikosai (2014) Timeline follow-back.

19. Sobell LC, Sobell MB (1995) Alcohol consumption measures. Assessing Alcohol Problems: A Guide for Clinicians and Researchers. National Institute on Alcohol Abuse and Alcoholism Pp: 55-73.

20. Miller WR (1999) Toward a theory of motivational interviewing. Motivational Interviewing Newsletter: Updates, Education and training 6(3): 2-4.

21. Miller WR, Rollnick S (1991) Motivational interviewing: Preparing people to change addictive behavior.Journal of Community \& Applied Social Psychology 2(4): 299-300.

22. Department of mental health (2014) Depressive screening test.

23. Whitfield JB (2001) Gamma glutamyl transferase. Critical reviews in clinical laboratory sciences $38(4)$ : 263-355.

24. Longabaugh R, Woolard RE, Nirenberg TD, Minugh AP, Becker B, et al. (2001) Evaluating the effects of a brief motivational intervention for injured drinkers in the emergency department. Journal of studies on alcohol 62(6): 806-816. 


\section{Psychology \& Psychological Research International Journal}

25. Freyer-Adam J, Coder B, Baumeister SE, Bischof G, Riedel J, et al. (2008) Brief alcohol intervention for general hospital inpatients: a randomized controlled trial. Drug Alcohol Depend 93(3): 233-243.

26. Norcross JC, Wampold BE (2011) Evidence-based therapy relationships: Research conclusions and clinical practices. Psychotherapy 48(1): 98-102.

27. Connors G J, Donovan D M, DiClemente CC (2001) Substance Abuse Treatment and the Stages of Change 4-13.

28. Vasilaki E I, Hosier SG, Cox W M (2006) The efficacy of motivational interviewing as a brief intervention for excessive drinking: a meta-analytic review. Alcohol Alcohol 41(3): 328-335.

29. Mundle G, Ackermann K, Munkes J, Steinle D, Mann K (1999) Influence of age, alcohol consumption and abstinence on the sensitivity of carbohydratedeficient transferrin, gamma-glutamyl transferase and mean corpuscular volume. Alcohol Alcohol 34(5): 760-766.

30. Helander A, Tabakoff B (1997) Biochemical markers of alcohol use and abuse: experiences from the Pilot Study of the WHO/ISBRA Collaborative project on state and trait markers of alcohol. Alcohol and Alcoholism 32(2): 133-144. 